\title{
Phosphoprotein Phosphatase PP2A Regulation of Insulin Receptor Substrate 1 and Insulin Metabolic Signaling
}

\author{
Chirag Mandavia ${ }^{\mathrm{a}}$ James R. Sowers ${ }^{\mathrm{a}-\mathrm{c}}$ \\ Departments of anternal Medicine and ${ }^{\mathrm{b}}$ Medical Pharmacology and Physiology, \\ University of Missouri-Columbia School of Medicine, and 'Harry S. Truman VA Medical Center, \\ Columbia, Mo., USA
}

\section{Key Words}

Cell signaling $\cdot$ Hormones $\cdot$ Cytokines $\cdot$ Receptors

\begin{abstract}
Insulin (INS) metabolic signaling is important for normal cardiovascular and renal function as well as for exerting the classic actions of INS, such as glucose uptake in skeletal muscle tissue. There is emerging evidence that tyrosine phosphatases as well as protein kinases have important modulating roles in INS metabolic signaling in both cardiovascular and classically INSsensitive tissues. For example, increases in phosphatase activity may partially explain how angiotensin II and aldosterone attenuate activation of the INS receptor substrate protein 1 (IRS-1)-phosphatidylinositol 3 kinase-protein kinase B pathway, thereby promoting INS resistance. On the other hand, phosphatase activation may also exert beneficial and cardiovascular protective effects in conditions such as overnutrition by blocking serine phosphorylation of IRS1, thereby improving downstream INS metabolic signaling. Both the beneficial and the detrimental effects exerted by the activation of phosphatases will be covered in this report.
\end{abstract}

Copyright $\odot 2012$ S. Karger AG, Basel

\section{Introduction}

The insulin receptor substrate protein 1 (IRS-1) is a convergence point for the insulin (INS) signaling pathway. IRS-1 is an important docking site for both the INS receptor and phosphatidylinositol 3 kinase (PI3K), the upstream and downstream components of the INS 


\section{CardioRenal Medicine}

\begin{tabular}{l|l}
\hline \multicolumn{2}{l}{ Cardiorenal Med 2012;2:308-313 } \\
\hline $\begin{array}{l}\text { DOI: 10.1159/000343889 } \\
\text { Published online: November 16, } 2012\end{array}$ & $\begin{array}{l}\text { @ } 2012 \text { S. Karger AG, Basel } \\
\text { www.karger.com/crm }\end{array}$ \\
\hline $\begin{array}{l}\text { Mandavia et al.: Phosphoprotein Phosphatase PP2A Regulation of Insulin Receptor } \\
\text { Substrate } 1 \text { and Insulin Metabolic Signaling }\end{array}$
\end{tabular}

metabolic signaling pathway $[1,2]$. IRS-1 is regulated, at least in part, by post-translational phosphorylation, with tyrosine phosphorylation of its residues in the phosphotyrosine-binding domain (PTB) and at YXXM motifs in the Src homology and IRS-1 NPXY motif-containing domain (SAIN) allowing the binding of the INS receptor and PI3K, respectively. In contrast, phosphorylation at IRS-1 serine residues can cause IRS-1 proteasomal degradation and impede IRS-1 engagement with PI3K [3-5]. Serine-threonine kinases, such as ribosomal protein p70 S6 kinase 1 (S6K1), a downstream effector of mammalian target of rapamycin (mTOR), promote serine phosphorylation of IRS-1 residues and reduced INS metabolic signaling [4-9]. Reduced INS metabolic signaling, in turn, leads to reduced myocardial and skeletal muscle glucose uptake, impaired nitric oxide (NO) production in endothelial cells, and reduced myocardial glycogen synthase activity and generation of ATP [4, 8-15]. There is emerging evidence that hormones such as Ang II and aldosterone converge with overnutrition in promoting mTOR/S6K1 signaling, serine phosphorylation of IRS-1, and reduced INS metabolic signaling in cardiovascular and conventionally INS-sensitive tissues [4-7].

Protein kinases and tyrosine phosphatases provide complimentary and countervailing actions in the modulation of INS metabolic signaling. For example, protein tyrosine phosphatase (PTP-1B) induction mediated by the activation of its protein kinase A (PKA) attenuates IRS-1-PI3K-Akt signaling and INS metabolic signaling [16]. Other phosphatases, such as the tyrosine phosphatase Src homology-containing protein 2 (SHP-2), which binds to the C-terminus of IRS-1, and the lipid phosphatase and tensin homology protein (PTEN), which plays an important role in regulating the PI3K/AKT anti-apoptotic and survival pathway, have also been implicated in influencing INS metabolic signaling $[17,18]$. Conversely, the role of serine-threonine phosphatases, such as protein phosphatase 1 (PP1) and protein phosphatase 2A (PP2A), has not been fully elucidated. In this regard, it has been shown that okadaic acid, which inhibits PP2A activity by over $90 \%$, is a negative regulator of INS metabolic signaling. Further, treatment of cells with okadaic acid reduces tyrosine phosphorylation but increases serine phosphorylation and degradation of IRS-1 [19-22]. Indeed, PP2A phosphatase may exert beneficial cardiovascular effects by attenuating mTOR/S6K1 and other serine kinase-mediated serine phosphorylation of IRS-1, thereby improving IRS-1 engagement with PI3K and downstream INS metabolic signaling.

Serine-threonine phosphatase PP2A consists of a scaffolding unit, which can bind to multiple regulatory subunits to exert substrate specificity, and a catalytic subunit, which exerts its enzymatic activity [21, 22]. The scaffolding unit is composed of huntingtin-elongation-A subunit-TOR (HEAT) repeats, with the TOR subunit of the HEAT (corresponding to the ' $T$ ') being equivalent to the yeast TOR1 and TOR2 genes [22, 23]. Phosphatases such as PP2A may be anchored (bound) to their substrates, usually through the scaffolding unit, which also anchors kinases. Such regulatory complexes are therefore able to exert a constitutive balancing effect on phosphorylation and respond appropriately to positive or negative triggers [24]. PP2A has been implicated in multiple aspects of the INS signaling pathway. In addition to direct dephosphorylation of the mTOR substrate S6K1, PP2A is thought to be involved in mTOR-mediated IRS-1 phosphorylation through modulation of PP2A activity by mTOR [25]. In addition, PP2A dephosphorylates protein kinase B (Akt) as well as adenosine monophosphate-activated protein kinase (AMPK), which are both involved in glucose transporter type 4 (GLUT 4) translocation and glucose uptake [26, 27]. PP2A can also activate the capping protein $4 \mathrm{E}-\mathrm{BP} 1$, which is involved in the modulation of translation and protein synthesis, such as inhibiting translation mediated by eukaryotic initiation factor eIF4E [28]. Thus, PP2A may positively regulate IRS-1/PI3K/INS metabolic signaling while counteracting the growth actions of serine kinases such as S6K1.

Ang II, aldosterone, and overnutrition activate mTOR/S6K1 signaling, leading to diminished INS metabolic signaling and biological consequences such as impaired NO-mediated 


\section{CardioRenal Medicine}

\begin{tabular}{l|l}
\hline Cardiorenal Med 2012;2:308-313 \\
\hline DOI: 10.1159/000343889 & $\begin{array}{l}\text { @ 2012 S. Karger AG, Basel } \\
\text { www.karger.com/crm }\end{array}$ \\
\hline Published online: November 16, 2012 &
\end{tabular}

Mandavia et al.: Phosphoprotein Phosphatase PP2A Regulation of Insulin Receptor

Substrate 1 and Insulin Metabolic Signaling

vascular relaxation [4, 5, 29-31]. Chronic Ang II and aldosterone exposure can cause INS resistance through signaling via the Ang II type 1 (AT1) and the mineralocorticoid receptor, which is ameliorated, at least partially, by AT1 receptor (AT1R) and mineralocorticoid receptor blockers [4, 7, 9, 29-31]. Ang II, like INS [6], also has beneficial effects on the vasculature, such as vasodilation through increased NO production mediated by the Ang II type 2 receptor (AT2R) $[4,9]$. For example, cardiac AT2R expression is increased in heart failure and serves to mediate beneficial compensatory protective effects [9]. Attenuation of IRS-1 degradation mediated by increased PP2A signaling may be an additional beneficial effect of AT2R signaling. Conversely, during chronic Ang II signaling in the cardiac adaptive/hypertrophic stage, AT1R is upregulated and causes excessive serine-threonine phosphorylation of IRS-1 mediated by several kinases, while PP2A may exert a counterbalancing effect.

$\mathrm{S} 6 \mathrm{~K} 1$ phosphorylation and activation in the heart is primarily mediated by the mTORRaptor complex 1 (mTORC1), and this complex is activated by multiple signals such as those from extracellular nutrients, increased Ang II, aldosterone, and sustained elevated INS levels [4, 7-11, 32-35]. Accordingly, we have postulated that PP2A may be able to bind IRS-1 in a complex with mTORC1 and inhibit these effects mediated by S6K. Thus, PP2A may be associated with IRS-1 either through its SAIN domain or in a kinase-phosphatase-balancing complex (mTOR-Raptor scaffold-PP2A complex) and may prevent serine phosphorylation of IRS-1. We have explored this notion in cell culture studies.

\section{Materials and Methods}

Cell Culture and Treatments and Generation of a Stable Cell Line Overexpressing GFP-Tagged IRS-1 Protein

Murine HL-1 cardiomyocytes, provided by Dr. William Claycomb, were cultured in growth medium. After $72 \mathrm{~h}$, the medium was replaced with starvation medium lacking fetal bovine serum and the cells were treated with norepinephrine to induce cell differentiation and prime the cells for response to treatments. HL-1 cells were subsequently treated with various compounds over $10 \mathrm{~h}$. Where indicated, pretreatments were done for $1 \mathrm{~h}$ before addition of the experimental compound. After this, cells were washed thrice in ice-cold DPBS buffer and collected by gentle scraping and centrifugation at $4{ }^{\circ} \mathrm{C}$ for immunoblotting studies. For these experiments, frozen cell pellets were lysed with $1 \%$ NP-40-containing buffer supplemented with standard protease and phosphatase inhibitors. Protein amounts were equalized using BCA and loaded onto 4-20\% gradient gels for SDS-PAGE, transferred to nitrocellulose or membranes, and probed with antibodies. For co-immunoprecipitation studies, cell lysates were incubated with agarose-conjugated antibody, and resulting immune precipitates were probed.

\section{Results}

Co-immunoprecipitation showed a direct interaction of PP2A with IRS-1 in HL-1 cardiomyocytes (data not shown). Specifically, endogenous PP2A was pulled down from cells using an antibody specific to the catalytic subunit, and the complex was probed with antiIRS-1 antibody. In cells treated for $10 \mathrm{~h}$ with $300 \mathrm{nM}$ INS or $100 \mathrm{~nm}$ Ang II, there was a decreased association of IRS-1 with PP2A compared to control. Conversely, there was no change or a slight increase in PP2A-IRS-1 association upon overnight $(10 \mathrm{~h})$ treatment of cells with $10 \mathrm{nM}$ rapamycin, an inhibitor of the mTORC1 complex. In addition, pre-incubation with an AT1R blocker prior to Ang II and pre-incubation with rapamycin prior to Ang II or INS treatments increased the total amount of IRS-1 protein that co-immunoprecipitated with PP2A.

Under chronic stimulation with INS or Ang II, mTOR co-immunoprecipitated with the PP2A catalytic subunit in a pull-down experiment using antibody to the catalytic subunit of PP2A. Most of the mTOR fraction that was associated with PP2A was dephosphorylated, 


\section{CardioRenal Medicine}

\begin{tabular}{l|l}
\hline \multicolumn{2}{l}{ Cardiorenal Med 2012;2:308-313 } \\
\hline $\begin{array}{l}\text { DOI: 10.1159/000343889 } \\
\text { Published online: November 16, } 2012\end{array}$ & $\begin{array}{l}\text { @ } 2012 \text { S. Karger AG, Basel } \\
\text { www.karger.com/crm }\end{array}$ \\
\hline $\begin{array}{l}\text { Mandavia et al.: Phosphoprotein Phosphatase PP2A Regulation of Insulin Receptor } \\
\text { Substrate } 1 \text { and Insulin Metabolic Signaling }\end{array}$
\end{tabular}

Table 1. Data supporting a direct association of IRS-1 and mTOR with PP2A

1 Analysis of IRS-1 using motif prediction software (MOTIF, which encompasses 6 different databases including PROSITE, PFAM, and other databases) shows the presence of signatures corresponding to ankyrin-repeat motifs involved in protein-protein interactions. Such repeats are found in protein phosphatase PP1 regulatory subunits in cardiomyocytes.

2 PP2A has been shown to modulate potassium channels in cardiomyocytes through AT2R and glycogen synthase kinase (GSK-3) signaling.

3 Ang II has been shown to activate PP2A through AT2R signaling.

4 The scaffolding unit of PP2A contains TOR repeats, which are similar to mTOR.

5 IRS-1 co-immunoprecipitates with the mTOR scaffolding protein Raptor, and mTOR may modulate IRS-1 degradation via its complexing with PP2A.

6 Protein phosphatase PP2A activity can be inhibited by PI3K signaling in hepatocytes.

7 The putative mTOR direct phosphorylation (binding?) motif at serine 636/639 of IRS- 1 is in a structurally ordered region of the protein (followed immediately by a short disordered region), which may allow stable binding of the mTOR-Raptor scaffold-PP2A scaffold complex.

8 The catalytic subunit of PP2A has been shown to bind alpha4 docking protein (the yeast TAP42 homologue); mTOR is able to phosphorylate this complex and therefore inactivate it (unknown which component). This process restrains the phosphatases and their effects on S6K1 phosphorylation/activation and capping protein 4E-BP.

suggesting that mTOR dissociation from PP2A is a prerequisite to its phosphorylation. Ang II and INS increased the total cardiomyocyte cell protein phosphatase activity associated with PP2A. Treatment with an AT1R blocker maintained PP2A activity at basal levels.

\section{Discussion}

Resistance to metabolic signaling by INS in cardiovascular and renal tissue as well as classic sites of INS action is one of the cardinal features of the cardiorenal metabolic syndrome $[4-6,10]$. The protein levels and phosphorylation status of IRS-1 docking protein are critical determinants of INS metabolic signaling [4-6]. IRS-1 is regulated by tyrosine as well as serine-threonine phosphorylation on its residues. Tyrosine phosphorylation of IRS-1 is necessary for downstream INS metabolic signaling and consequent increased glucose uptake in heart and skeletal muscle as well as increased NO production in endothelial cells [4-6]. In contrast, serine-threonine phosphorylation of IRS-1 leads to the inhibition of INS signaling, INS resistance, and IRS-1 degradation. The mTOR/S6K1 signaling pathway is activated by overnutrition and hormones such as Ang II and aldosterone which promote IRS-1 serine phosphorylation and decreased INS metabolic signaling.

The scaffolding unit of protein phosphatase PP2A contains TOR repeats similar to mTOR and its scaffold Raptor, and has been hypothesized to mediate IRS-1 degradation through regulation of its activity by mTOR [34-37]. These studies demonstrated that IRS-1 was able to be precipitated (complexed) with Raptor in cultured cells. Since PP2A activation has been hypothesized to modulate IRS-1 degradation, this regulation of IRS-1 may partially be mediated by PP2A complexed with mTOR/Raptor.

The current data suggest that IRS-1 normally exists in a complex with PP2A, which may serve to protect IRS-1 against excessive serine phosphorylation and degradation. Sustained 


\section{CardioRenal Medicine}

\begin{tabular}{l|l}
\hline Cardiorenal Med 2012;2:308-313 \\
\hline DOI: 10.1159/000343889 & $\begin{array}{l}\text { @ 2012 S. Karger AG, Basel } \\
\text { www.karger.com/crm }\end{array}$ \\
\hline Published online: November 16, 2012 &
\end{tabular}

Mandavia et al.: Phosphoprotein Phosphatase PP2A Regulation of Insulin Receptor Substrate 1 and Insulin Metabolic Signaling

INS and Ang II treatments were able to reduce the amount of IRS-1 protein that was complexed with PP2A, and this was reversed by pre-treatments with an AT1R blocker and the mTORC1 inhibitor rapamycin. These data suggest that there is a protective role for PP2A to maintain IRS-1 protein and IRS-1 tyrosine phosphorylation in INS metabolic signaling. In the current study, there was negligible phosphorylation in the total pool of mTOR that pulled down with PP2A, indicating that PP2A may also be protective against mTOR/S6K1-mediated IRS-1 serine phosphorylation. Ang II and INS increased total cellular PP2A activity in cardiomyocytes, which was blocked by an AT1R blocker and partially inhibited by the mTORC1 inhibitor rapamycin. This may indicate a compensatory increase in phosphatase activity to counterbalance the excessive stimulation of serine kinases as a result of chronic exposure to excess Ang II and INS. In addition to our results, empirical data support our prediction of a direct constitutive association of IRS-1 with PP2A [34-38] (table 1).

Thus, cumulative data suggest that PP2A may directly interact with mTOR and/or Raptor through its scaffold subunit, which contains HEAT (TOR) repeats similar to those in Raptor, and thus be associated with an IRS-1 complex in which mTOR may variably compete for direct binding on serine residues of IRS depending on its association with PP2A and the protein folding existing under different exogenous signals. The current data also support an important role for PP2A in influencing INS metabolic signaling. Previous studies showed that IRS-1 co-immunoprecipitates in a complex with the mTOR scaffold protein Raptor. Accordingly, PP2A activity serves to counterbalance the actions of mTOR/S6K1 signaling to promote degradation of IRS-1. Further studies are needed to understand the precise mechanism underlying these complex interactions.

\section{Acknowledgements}

This research was supported by the NIH (R01 HL73101-01A1 and R01 HL107910-01 to J.R.S.) and the Veterans Affairs Merit System 0019 (to J.R.S.). The authors would like to thank Brenda Hunter for her assistance in editing the manuscript.

\section{References}

1 Wolf G, Trub T, Ottinger E, Groninga L, Lynch A, White MF, Miyazaki M, Lee J, Shoelson SE: PTB domains of IRS-1 and Shc have distinct but overlapping binding specificities. J Biol Chem 1995;270:27407-27410.

$>2$ White MF: The IRS-signaling system: a network of docking proteins that mediate insulin action. Mol Cell Biochem 1998;182:3-11.

-3 Gual P, Le Marchand-Brustel Y, Tanti JF: Positive and negative regulation of insulin signaling through IRS-1 phosphorylation. Biochimie 2005;87:99-109.

-4 Pulakat L, Demarco VG, Ardhanari S, Chockalingam A, Gul R, Whaley-Connell AT, Sowers JR: Adaptive mechanisms to compensate for overnutrition-induced cardiovascular abnormalities. Am J Physiol Regul Integr Comp Physiol 2011;301:R885-R895.

5 Sowers JR, Whaley-Connell A, Hayden MR: The role of overweight and obesity in the cardiorenal syndrome. Cardiorenal Med 2011;1:5-12.

6 Muniyappa R, Sowers JR: Endothelial insulin and IGF-1 receptors: when yes means NO. Diabetes 2012;61:2225-2227.

$\checkmark 7$ Kim JA, Jang HJ, Martinez-Lemus LA, Sowers JR: Activation of mTOR/p70S6 kinase by ANG II inhibits insulinstimulated endothelial nitric oxide synthase and vasodilation. Am J Physiol Endocrinol Metab 2012;302:E201-E208.

-8 Paz K, Hemi R, LeRoith D, Karasik A, Elhanany E, Kanety H, Zick Y: A molecular basis for insulin resistance. Elevated serine/threonine phosphorylation of IRS-1 and IRS-2 inhibits their binding to the juxtamembrane region of the insulin receptor and impairs their ability to undergo insulin-induced tyrosine phosphorylation. J Biol Chem 1997;272: 29911-29918.

-9 Pulakat L, Aroor AR, Gul R, Sowers JR: Cardiac insulin resistance and microRNA modulators. Exp Diabetes Res 2012; 2012:654904.

10 Whaley-Connell A, Sowers JR: Indices of obesity and cardiometabolic risk. Hypertension 2011;58:991-993. 


\section{CardioRenal Medicine}

\begin{tabular}{|c|c|}
\hline Cardiorenal Med 2012;2:308-313 & \\
\hline $\begin{array}{l}\text { DOI: } 10.1159 / 000343889 \\
\text { Published online: November } 16,2012\end{array}$ & $\begin{array}{l}\text { (c) } 2012 \text { S. Karger AG, Basel } \\
\text { www.karger.com/crm }\end{array}$ \\
\hline
\end{tabular}

Mandavia et al.: Phosphoprotein Phosphatase PP2A Regulation of Insulin Receptor Substrate 1 and Insulin Metabolic Signaling

11 Zhang J, Gao Z, Yin J, Quon MJ, Ye J: S6K directly phosphorylates IRS-1 on Ser-270 to promote insulin resistance in response to TNF-(alpha) signaling through IKK2. J Biol Chem 2008;283:35375-35382.

12 Salt IP, Morrow VA, Brandie FM, Connell JM, Petrie JR: High glucose inhibits insulin-stimulated nitric oxide production without reducing endothelial nitric-oxide synthase Ser1177 phosphorylation in human aortic endothelial cells. J Biol Chem 2003;278:18791-18797.

13 Lastra G, Habibi J, Whaley-Connell AT, Manrique C, Hayden MR, Rehmer J, Patel K, Ferrario C, Sowers JR: Direct renin inhibition improves systemic insulin resistance and skeletal muscle glucose transport in a transgenic rodent model of tissue renin overexpression. Endocrinology 2009;150:2561-2568.

Kim J, Wei Y, Sowers JR: Role of mitochondrial dysfunction in insulin resistance. Circ Res 2008;102:401-414.

Egawa K, Nakashima N, Sharma PM, Maegawa H, Nagai Y, Kashiwagi A, Kikkawa R, Olefsky JM: Persistent activation of phosphatidylinositol 3-kinase causes insulin resistance due to accelerated insulin-induced insulin receptor substrate-1 degradation in 3T3-L1 adipocytes. Endocrinology 2000;141:1930-1935. Ketsawatsomkron P, Stepp DW, Fulton DJ, Marrero MB: Molecular mechanism of angiotensin II-induced insulin resistance in aortic vascular smooth muscle cells: roles of Protein Tyrosine Phosphatase-1B. Vascul Pharmacol 2010;53: $160-168$.

17 Ozes ON, Akca H, Mayo LD, Gustin JA, Maehama T, Dixon JE, Donner DB: A phosphatidylinositol 3-kinase/Akt/ mTOR pathway mediates and PTEN antagonizes tumor necrosis factor inhibition of insulin signaling through insulin receptor substrate-1. Proc Natl Acad Sci USA 2001;98:4640-4645.

18 Hanke S, Mann M: The phosphotyrosine interactome of the insulin receptor family and its substrates IRS-1 and IRS2. Mol Cell Proteomics 2009;8:519-534.

Mothe I, Van Obberghen E: Phosphorylation of insulin receptor substrate-1 on multiple serine residues, 612, 632, 662, and 731, modulates insulin action. J Biol Chem 1996;271:11222-11227.

Zhou X, Ma L, Habibi J, Whaley-Connell A, Hayden MR, Tilmon RD, Brown AN, Kim JA, Demarco VG, Sowers JR: Nebivolol improves diastolic dysfunction and myocardial remodeling through reductions in oxidative stress in the Zucker obese rat. Hypertension 2010;55:880-888. Janssens V, Goris J: Protein phosphatase 2A: a highly regulated family of serine/threonine phosphatases implicated in cell growth and signalling. Biochem J 2001;353:417-439. Shi Y: Serine/threonine phosphatases: mechanism through structure. Cell 2009;139:468-484. Helliwell SB, Wagner P, Kunz J, Deuter-Reinhard M, Henriquez R, Hall MN: TOR1 and TOR2 are structurally and functionally similar but not identical phosphatidylinositol kinase homologues in yeast. Mol Biol Cell 1994;5:105-118. Zhou AY, Ichaso N, Adamarek A, Zila V, Forstova J, Dibb NJ, Dilworth SM: Polyomavirus middle T-antigen is a transmembrane protein that binds signaling proteins in discrete subcellular membrane sites. J Virol 2011;85:3046-3054.

25 Hartley D, Cooper GM: Role of mTOR in the degradation of IRS-1: regulation of PP2A activity. J Cell Biochem 2002; 85:304-314.

26 Ni YG, Wang N, Cao DJ, Sachan N, Morris DJ, Gerard RD, Kuro-O M, Rothermel BA, Hill JA: FoxO transcription factors activate Akt and attenuate insulin signaling in heart by inhibiting protein phosphatases. Proc Natl Acad Sci USA 2007;104:20517-20522.

27 Li Q, Li J, Ren J: UCF-101 mitigates streptozotocin-induced cardiomyocyte dysfunction: role of AMPK. Am J Physiol Endocrinol Metab 2009;297:E965-E973.

28 Nho RS, Peterson M: Eukaryotic translation initiation factor 4E binding protein 1 (4EBP-1) function is suppressed by Src and protein phosphatase 2A (PP2A) on extracellular matrix. J Biol Chem 2011;286:31953-31965.

29 Habibi J, Hayden MR, Sowers JR, Pulakat L, Tilmon RD, Manrique C, Lastra G, Demarco VG, Whaley-Connell A: Nebivolol attenuates redox-sensitive glomerular and tubular mediated proteinuria in obese rats. Endocrinology 2011; 152:659-668.

30 Ren J, Pulakat L, Whaley-Connell A, Sowers JR: Mitochondrial biogenesis in the metabolic syndrome and cardiovascular disease. J Mol Med (Berl) 2010;88:993-1001.

-31 Tremblay F, Krebs M, Dombrowski L, Brehm A, Bernroider E, Roth E, Nowotny P, Waldhäusl W, Marette A, Roden M: Over-activation of S6 kinase 1 as a cause of human insulin resistance during increased amino acid availability. Diabetes 2005;54:2674-2684.

-32 Tzatsos A: Raptor binds the SAIN (Shc and IRS-1 NPXY binding) domain of insulin receptor substrate-1 (IRS-1) and regulates the phosphorylation of IRS-1 at Ser-636/639 by mTOR. J Biol Chem 2009;284:22525-22534.

- 33 Tzatsos A, Kandror KV: Nutrients suppress phosphatidylinositol 3-kinase/Akt signaling via raptor-dependent mTORmediated insulin receptor substrate 1 phosphorylation. Mol Cell Biol 2006;26:63-76.

-34 Vasudevan NT, Mohan ML, Gupta MK, Hussain AK, Naga Prasad SV: Inhibition of protein phosphatase 2A activity by PI3K $\gamma$ regulates $\beta$-adrenergic receptor function. Mol Cell 2011;41:636-648.

-35 Nojima H, Tokunaga C, Eguchi S, Oshiro N, Hidayat S, Yoshino K, Hara K, Tanaka N, Avruch J, Yonezawa K: The mammalian target of rapamycin (mTOR) partner, raptor, binds the mTOR substrates p70 S6 kinase and 4E-BP1 through their TOR signaling (TOS) motif. J Biol Chem 2003;278:15461-15464.

-36 Liu L, Chen L, Luo Y, Chen W, Zhou H, Xu B, Han X, Shen T, Huang S: Rapamycin inhibits IGF-1 stimulated cell motility through PP2A pathway. PLoS One 2010;5:e10578.

-37 Hahn K, Miranda M, Francis VA, Vendrell J, Zorzano A, Teleman AA: PP2A regulatory subunit PP2A-B' counteracts S6K phosphorylation. Cell Metab 2010;11:438-444.

38 Stull AJ, Wang ZQ, Zhang XH, Yu Y, Johnson WD, Cefalu WT: Skeletal muscle protein tyrosine phosphatase 1B regulates insulin sensitivity in African Americans. Diabetes 2012;61:1415-1422. 